\title{
Disease Characterization and Skin as a Metabolizing Organ
}

The present issue of the Skin Pharmacology and Physiology journal brings exciting new aspects. Three of them should be mentioned forehand: disease characterization with non-invasive biophysical instrumentation, namely leprosy, the concept of skin as a metabolizing organ and the importance of nutrition for skin functions.

The cutaneous metabolism of topically applied substances is an emerging area in skin research. Since very little is known about the skin as a metabolic organ, the metabolism of topically applied substances in the skin is probably underestimated. Rolsted et al. (Skin Pharmacol Physiol 2009;22:124-127) studied the metabolism of topically applied lidocaine in vivo. Two hours after the topical administration they detected a lidocaine metabolite, namely monoethylglycine xylidide, in skin biopsies. The authors conclude that lidocaine is metabolized in human skin after topical application.

In a British-German collaboration the effects of different vehicles on skin hydration were studied in vivo. Wiedersberg et al. (Skin Pharmacol Physiol 2009;22:128-130) showed that stratum corneum hydrating can be modulated by the respective vehicle components.

Song et al. (Skin Pharmacol Physiol 2009;22:131-136) characterized stratum corneum functions in patients recovered from leprosy in a Chinese-San Francisco collaborative study. Leprosy is a widely spread disease in tropical and subtropical countries involving both the skin and the peripheral nerve system. The authors studied 43 cured leprosy patients and 29 control subjects. They detected decreased stratum corneum hydration and elevated surface $\mathrm{pH}$ in cured leprosy, while epidermal barrier homeostasis was unaltered. Furthermore, different subtypes of leprosy where characterized.

Jeon and his research group (Skin Pharmacol Physiol 2009;22:137-141) studied the protective effects of oral epigallocatechin gallate supplementation in hairless rats.

Mitriaikina and Müller-Goymann (Skin Pharmacol Physiol 2009;22:142-150) report about the permeation of non-diluted and diluted betamethasone valerate in different formulations. They were able to show that the permeation rate can be differentiated in isolated human stratum corneum and artificial skin constructs. The differences in permeation depend on the type of the formulation and the water content of the formulation.

Philips et al. (Skin Pharmacol Physiol 2009;22:151157) studied the differential effects of ceramides in preventing epidermal hyperplasia. Furthermore, they were able to show an extracellular matrix remodelling in keratinocytes and fibroblasts.

Drakaki et al. (Skin Pharmacol Physiol 2009;22:158165) characterized and differentiated basal cell carcinoma from normal tissue by reflectance spectroscopy. The authors could demonstrate that laser-induced fluorescence spectroscopy is capable of differentiating neoplastic from normal tissue.

A German-Dutch collaboration, namely Coelho Palermo Cunha et al. (Skin Pharmacol Physiol 2009;22: 166-176) showed an inhibition of photo-carcinogenesis by a topically applied ultraviolet B absorber in hairless albino rats.

If you are interested in the activities of the International Society of Skin Pharmacology and Physiology (ISP), we would like to invite you to join us for the preGordon-Research-Conference meeting to be held in Boston on August 9th, 2009. Please look for the programme update at the ISP homepage (www.isp-society.org).

Joachim Fluhr, President of the ISP Jürgen Lademann, Editor

\begin{tabular}{ll}
\hline KARGER & @ 2009 S. Karger AG, Basel \\
Fax $+41660-5527 / 09 / 0223-0123 \$ 26.00 / 0$ \\
$\begin{array}{l}\text { E-Mail karger@karger.ch } \\
\text { www.karger.com }\end{array}$ & $\begin{array}{l}\text { Accessible online at: } \\
\text { www.karger.com/spp }\end{array}$
\end{tabular}

